\title{
A PRESTAÇÃO DE JUSTIÇA NA SOCIEDADE DE MASSAS: Ensaio Sobre Estética, Cultura e Justiça em Tempos Pós-Modernos
}

THE SUPPLY OF JUSTICE IN MASS SOCIETY. Essay on Aesthetics, Culture and Justice in Post-Modem Times

\author{
Eduardo Curlos Bianca Bittar
}

\begin{abstract}
Resumo:
A discussão sobre a justiça na dinâmica interna da sociedade contemporânea importa na necessidade de compreensão do discurso que preside as relações sociais, de modo que a análise da estética contemporânea pode fornecer elementos curiosos para a avaliação metafórica do problema da decisão de justiça dentro do ambiente judiciário hodierno.
\end{abstract}

Palavras-chave: Justiça. Técnica. Judiciário. Pós-modernidade.

Abstract:

The debate on justice in the inner dynamics of contemporary society implies the understanding of the speech that govem social relationships, by the way that the analysis of contemporary aesthetics may result in curious elements for the metaphoric evaluation of decision of justice problem in the modern judiciary environment.

Keywords: Justice. Techniques. Judiciary Power. Post-Modernity.

\section{Problematização}

A presente investigação verte-se no sentido de compreender como o Estado tem praticado e devolvido justiça à sociedade contemporânea. A justiça evocada nesta perspectiva de análise é a justiça das práticas judiciárias, o que implica um questionamento sobre o modus de produção de decisões pelo Judiciário, já que não é fora desta instituição, que se encarna a idéia da reparação à injustiça sofrida e nãosolucionada no ambiente social. O duplo papel do Estado, formulado e desenvolvido pela modernidade, é, em primeiro lugar, o de prescrever regras de justiça e de prover de justiça a sociedade conforme estas regras. e, em segundo lugar, o de distribuir justiça e permitir com que as infrações às regras de justiça fixadas sejam, também, passiveis de reparação (ecoando idéias de recompensa, punição, retribuição, restituição, retorno ao status quo ante, reparação, devolução...).

Livre-Docente e Doutor. Professor Associado do Departamento de Filosofia e Teoria Geral do Direito da Faculdade de Direito da Universidade de São Paulo (USP). Membro do Conselho Editorial da Revista da Faculdade de Direito da Universidade de São Paulo. Professor e Pesquisador do Programa de Mestrado em Direitos Humanos do UniFIEO. Secretário-Executivo da Associação Nacional de Direitos Humanos (ANDHEP). Membro do Núcleo de Estudos da Violència (NEV-USP). 
A descarnada forma de atuação do Estado-juiz, no entanto, tem conduzido diversos questionamentos. Por isso, na medida em que se converte este tema e problema de pesquisa, se trata de perceber que uma série de transformações da vida contemporânea, da sociedade pós-moderna,' irão afetar diretamente a dimensão de organização e estruturação das práticas de justiça. Que transformações são estas e como elas afetam estas práticas? A tarefa, portanto, desta pesquisa é a de compreender este modus pelo qual se produz justiça em tempos pós-modernos, e sob que premissas, paradigmas e pressões. Trata-se de compreender o processo de infirmação da qualidade da justiça que se faz e que se pratica.

Este questionamento, por sua vez, envolve a necessidade de compreender a própria sociedade pós-moderna, diagnóstico que não pode ser feito, senão a partir da avaliação do próprio indivíduo e das práticas sociais que o cercam. Individuação e socialização são as duas faces de um mesmo processo. Por isso, é possível colher diversos vestígios das práticas sociais, a partir da análise de alguns fragmentos da estética contemporânea; aqui utilizada como termômetro cultural para um questionamento sobre a dimensão da técnica no Direito.

O ponto de partida metodológico é a projeção dos estudos críticos da Escola de Frankfurt, especialmente os de Adorno, Benjamim, Horkheimer, Marcuse e Habermas, para dentro da análise de questões concernentes à sociedade moderna e seus frutos, em especial o tema da racionalidade moderna. Se a teoria crítica foi capaz de produzir uma identificação clara das questões que margeiam a definição da dialética negativa da modernidade, e, em parte, de definir os indícios de crise da modernidade, torna-se um referencial teórico de extremo valor para um diagnóstico da vida pósmoderna. Os conceitos da teoria crítica serão entrelaçados ao estudo da estética da música eletrônica, esta utilizada como chave hermenêutica para a interpretação da ascensão e consagração da técnica na sociedade pós-moderna.

Neste sentido, a questão provocadora da análise pode ser colocada nos seguintes termos: quais as resultantes do processo de tecnificação da sociedade moderna, se considerada a questão das práticas hodiernas de justiça? A provocação para o debate jusfilosófico se justifica na medida em que se considera, juntamente com Horkheimer, que a "si la filosofia logra ayudar a los hombres a reconocer estos factores, habrá prestado un gran servicio a la humanidad. El método de negación, la denuncia de

Para uma análise mais delida do sentido desta expressão e do debate suscitado em torno dela, consulte-se BITTAR. Eduardo Carlos Bianca. O direilo na pós-modernidade. Rio de Janeiro: Forense Universitária, 2005. 
cuanto mutila a la humanidad e impide su libre desarrollo, descansa sobre la confianza en el ser humano..." 2

2. Modernidade e instrumentalização da razão: o triunfo da técnica

A modernidade traz consigo a idéia de que a razão, substituindo o mito e a metafísica, é capaz de solver toda forma de dominação, e, acima de tudo. de prover demandas de emancipação. A modernidade nasce otimista do processo de racionalização da sociedade. Da pré-modernidade em direção à modernidade está-se a falar da passagem da dimensão do impreciso para o preciso, da heterogeneidade à homogeneidade, do desordenado ao ordenado, do ambivalente ao certo, ao desconhecido ao conhecido, do natural ao artificial. ${ }^{3} \mathrm{O}$ cálculo, o exercício métrico da razão, que se imporá sobre o mundo das coisas, é parte do processo arquitetural e ordenador. Dominação, projeção, cálculo, configuração, organização, planejamento são atitudes de ação racional sobre o mundo da desordem. que precisa ser triado e esquadrinhado, antes de ser colocado à disposição para a utilização. ${ }^{4} \mathrm{~A}$ modernidade acaba por entronizar a perspectiva, segundo a qual se valoriza o técnico, e o técnico se superpõe a toda forma de sabedoria tradicional; o que não está para a técnica e para o uso. não pode ser reconhecido como significativo. O que é meramente especulativo ou não-científico deixa de ocupar sentido de proeminência.

Trata-se de moldar a realidade. a exemplo do que facem a arquitetura ou a jardinagem, modo que todo dado da natureza pode ser amoldado ao "construído" da razão. Avultam as pranchetas e os projetos, as imposições por decreto, o remanejamento das estruturas para estimular o comportamento racional, permitindo a eficácia do sistema que gera lucros. ${ }^{5} \mathrm{Na}$ medida em que tudo está fundamentado pelo ideário da utilidade para o bem-estar do homem, a razão se manifesta no Estado burocraticamente organizado, na nação sociologicamente construída. no território geográfico mapeado, na natureza cientificamente controlada. nos procedimentos produtivos fabris controlados

2 HORKHFIMER, Max. Critica de la razón instrumental. Buenos Aires: Ed. Sur. 1973. p. 187.

"A ciência moderna nasceu da esmagadora ambição de conquistar a Natureza c subordiná-la às necessidades humanas" (BAUMAN. Zygmunt. Modernidade e ambivalência. Rio de Janciro: Jorge Zahar, 1999. p. 48).

4 "Podemos dizer que a existência é moderna na medida em que é produzida e sustentada pelo projelo. manipulação, administração, planejamento. A existência é moderna na medida em que é administrada por agentes capazes (isto $\dot{c}$, que possuem conhecimento, habilidade e tecnologia) e soberanos. Os agentes são soberanos na medida em que reivindicam e defendem com sucesso o direito de gerenciar e administrar a existência: o direito de definir a ordem $e$, por conseguinte, pôr de lado o caos como refugo que escapa à definição" (BAUMAN, Zygmunt. Modernidade e ambivalência. Rio de Janeiru: Jorge Zahar, 1999. p. 15).

s Cf. BAUMAN, Zygmunt. Modernidade liquida. Tradução Plinio Dentzein. Rin de Janeiro: Jorge Zahar, 200I.p. 58. 
pela arquitetura das esteiras de produção e técnicas de mecanização do trabalho (cuja maior expressão foi o fordismo), ${ }^{6}$ nas doenças remediadas pela Medicina, nos corpos perigosos encarcerados pela prisão, etc. Aqui se manifesta a verdadeira ideologia da modernidade, qual seja "a racionalidade técnica hoje é a racionalidade da própria dominação. Ela é o caráter compulsivo da sociedade alienada de si mesma" ${ }^{7}$

O que não estava previsto (ou estava previsto, mas não estava calculado o efeito da desproporção causada a partir dos reflexos destes sobre o projeto inicial) no projeto moderno é que a razão emancipatória acabaria por se converter e de se reduzir a ser uma mera razão instrumental, como afirma Horkheimer, quando diz “... la reducción de la razón a mero instrumento va en última instancia en menoscabo incluso de su carácter instrumental..." \& A redução da razão emancipatória, por exemplo a de matriz kantiana, à mera razão instrumental, é uma das questões que a modernidade avançada dos tempos hodiernos ainda não logrou superar, e, pelo que se analisa a seguir, dá claros vestígios de produzir ainda piores resultados, especialmente contando-se com a acentuação de sua presença em diversos níveis de afirmação da vida social.

Ora, o processo de dominação da natureza, iniciado na modernidade, além

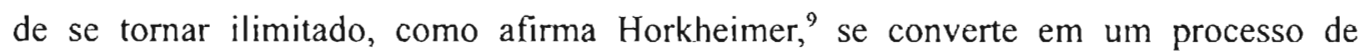
dominação de tudo o que é natural, de toda as formas de manifestação da natureza, e não fica dificil explicar que da natureza objetiva se passa a projetar a dominação também para o âmbito da natureza humana. A natureza submetida não é, portanto, somente a natureza objetiva, mas também a natureza humana. “... La historia de los esfuerzos del hombre por sojuzgar la naturaleza es también la historia del sojuzgamiento del hombre

6 "O fordismo era a autoconsciēncia da sociedade moderna em sua fase "pesada", "volumosa", ou "imóvel" e "enraizada", "sólida" Nesse estágio de sua história conjunta, capital, administração e trabalho estavam, para o bem e para o mal, condenados a ficar juntos por muito tempo, talvez para sempre - amarrados pela combinação de fábricas enormes, maquinaria pesada e força de trabalho maciça. Para sobreviver, e principalmente para agir de modo eficiente, tinham que "cavar", desenhar frontciras c marcá-las com trincheiras c arame farpado, ao mesmo tempo em que faziam a fortaleza suficientemente grande para abrigar todo o necessário para resistir a um cerco prolongado, talvez sem perspectivas. O capitalismo pesado era obcecado por volume e tamanho, e, por isso, também por fronteiras, fazendo-as firmes e impenetráveis. O gênio de Henry Ford foi descobrir o modo de manter os defensores de sua fortaleza industrial dentro dos muros - para guardá-los da tentação de desertar uu mudar de lado" (BAUMAN, Zygmunt. Modernidade liquida. Rio de Janeiro: Jorge Lahar, 2001. p. 69).

HORKHEIMER, Max; ADORNO. Theodor W. Dialética do esclarecimento: fragmentos filosóficos. Tradução Guido Antonio de Almeida. Rio de Janeiro: Jorge Zahar. 1985. p. 114.

8 HORKHEIMER, Max. Crilica de la razon instrumental. Buenos Aires: Ed. Sur, 197.3. p. 84.

9 “...Con todo, la naturaleza es considerada hoy más que nunca como un mero instrumento de los hombres. Es cl objeto de una explotación total. que no conoce objetivo alguno puesto por la razón. y, por lo tanto, ningún limite. El imperialismo limitado del hombre jamás se ve saciado... (HORKHEIMER, Max. Critica de la razón instrumental, cit., p. 127). 
por el hombre..." 10 Por isso, esta passa a ser vista mais e mais como apêndice da própria técnica.

3. Investigação da sociedade contemporânea: traços da estética eletrônica

A compreensão da sociedade contemporânea, uma sociedade complexa, implica necessariamente na análise de algum fragmento que possa ser tomado, como parte de um todo, um elemento de análise e medição dos processos de transformação da sociedade presente. Esta aferição reclama a aproximação e compreensão dos modos pelos quais a sociedade pratica seus valores, para o que o estudo do triunfo da estética eletrônica parece oferecer grande contribuição. Para além do fato de considerar que a obra de arte na era da sua reprodutibilidade perdeu a aura, há que se perceber que a reprodutibilidade se tornou a linguagem da própria música contemporânea. "A música eletrônica é tomada como chave-de-compreensão de práticas culturais hodiernas, ${ }^{12}$ por meio das quais se pode perceber o quanto o triunfo da técnica não-somente não deixou de ser engrandecido, como também se acentua. Já adiantavam Adorno e Horkheimer, na Dialética do esclarecimento, com respeito a isto, que "a maldição do progresso irrefreável é a irrefreável regressão" "Fste capítulo será, nesse sentido, importante para a investigação de uma questão que se quer fundamental de ser analisada na dimensão do debate sobre a justiça, o que se fará adiante.

Análise do individuo que emerge da cultura pós-moderna. o indivíduo eletronizado, possuído desde fora pelas teias de implementos técnicos que o circundam e o cercam, também é o individuo eletrificado por uma vida em aceleração, pelo dinamismo de uma vida em aceleração. Por isso, Zygmunt Bauman afirma: “Estar em movimento, antes um privilégio e uma conquista, torna-se uma necessidade. Manter-se em alta velocidade, antes uma aventura estimulante, vira uma tarefa cansativa. Mais importante, a desagradável incerteza e a irritante confusão, supostamente escorraçadas pela velocidade, recusam-se a sair de cena" ${ }^{14}$ A própria medição do tempo é testemunha

HORKHEIMER, Max. Crítica de la razón instrumental, cit., p. 125.

"Sobre a questão da perda da aura, vide BENJAMIN, Walter. A obra de arte na era de sua reprodutibilidade técnica. In: Obras escolhidas. Tradução Sergio Paulo Roaunet. 7. ed. São Paulo: Brasilense, 1994. p. 171.

12 Este é um objeto de estudo de grande interesse dos frankfurtianos, destacando-se os estudos de Walter Benjamim, que afirma: "A reprodução técnica do som iniciou-se no fim do século passado" (BENJAMIN, Walter. A obra de arte na era de sua reprodutibilidade técnica. In: Obras escolhidas. Tradução Sergio Paulo Roaunet. 7. ed. Säo Paulo: Brasilense, 1994. p. 167).

13 HORKHEIMER, Max; ADORNO, Theodor W. Dialética do esclarecimento: fragmentos filosóficos. Tradução Guido Antonio de Almeida. Rio de Janciro: Jorge Zahar, 1985. p. 46.

is BAl iMAN, Zygmunt. Amur Liquido: sobre a fragilidade dos laços humanos. Tradução Carlos Alberto Medeiros. Rio de Janeiro: Jorge Zahar, 2004. p. 13. 
desta aceleração da vida contemporânea, pois se faz em termos de segundos, e nem mais em termos de minutos, ou mesmo de horas.

$\mathrm{O}$ individuo pós-moderno é, neste sentido, um indivíduo acostumado com a dimensão do que é acelerado, tecnificado, celerizado, escasseado de profundidade, com o espectro da televisividade da vida; esta é composta por flashs instantâneos, estes que definem a própria passagem do tempo, onde o indivíduo se encontra na sensação de posse de um presente que se rarifica e escasseia de modo fluido a cada instante. Por isso, a estética haverá de refletir também a ascensão deste modus que se instale na vida quotidiana, e ritmiza as relações intersubjetivas numa temporalidade hiper-acelerada na perspectiva do tempo. As haves (shows de música eletrônica) são uma demonstração de como a estética contemporânea absorve esta passagem da técnica do ambiente da produção ou do estúdio para o ambiente da fruição estética. A linguagem musical é a do fliperama, reproduz um game e evoca o tempo todo rítmicas assemelhadas à da vida cibernética.

O operar é a própria arte que se quer ver demonstrada nos palcos onde atuam os Dj's. O operar, aqui, supera a dimensão do saber tocar $o$ instrumento em si mesmo, pois a música será somente a conjunção de ruídos e fragmentos de obras musicais. As vozes são eletronizadas, e não-evocam cantores, mas máquinas em processamento. DJ's são operadores de músicas e ruídos armazenados em grandes estoques virtuais de ritmos, sistemas de referências sonoras e musicais. Os resultados são canções de ritmos alucinantes, de altíssima acuidade eletrônica, mas que evocam máquinas-cantoras e vozes robotizadas, que fazem a descrição do homem que emerge neste contexto: o homem-máquina. Por isso, podem ser tomadas, para efeitos de análise, como chave hermenêutica de compreensão do estado atual da cultura e da estética contemporâneas. $^{15}$

O que há a ser considerado nestes eventos é o fato de que diversas tribos comparecem às haves; possuem identidades diversas, hábitos específicos, vestimentas as mais diversificadas. As diversas tribos surgem de diversas partes e partilham um mesmo espaço no entanto, acorrem a um evento onde o outro não é de modo algum considerado como um fim do processo de aglutinação coletiva; estão no mesmo espaço, mas nãocon-vivem. Estão ali, mas não estão ali, somente fazem parte de uma espécie de pano de fundo sutil, que preenche um horizonte diversificado de tendências da moda, da

A música assim posta traduz a perda de apelo à tradição: não se faz música, se reproduz sobre bases magnéticas e eletrônicas: "Generalizando, podemos dizer que a técnica de reprodução destaca do dominio da tradição o objeto reproduzido" (BENJAMIN, Walter. A obra de arte na era de sua reprodutibilidade técnica. In: . Obras escolhidas. Tradução Sergio Paulo Roaunet. 7. ed. São Paulo: Brasilense. 1994. p. 168). 
diversidade estética e da cultura consumista contemporâneas. Estar no mesmo espaço não significa troca. O respeito ao direito à diferença, no entanto, está garantido, especialmente num espaço em que ser diferente é ser homogêneo, e ser comum é ser diferente, estranho. Há o reconhecimento coletivo da estranheza como padrão.

$\mathrm{O}$ limite deste reconhecimento está na exigência de que o indivíduo ou o grupo respeite a ética da indiferença deste ambiente, deste locus simultaneamente cheio $e$ oco, e não-incorra no erro de tentar transpor fronteiras entre os diversos jogos-delinguagem dos micro-universos de discurso das diversas tribos, na linguagem de JeanFrançois Lyotard. ${ }^{16}$ Trata-se de uma grande audiência pública de música eletrônica. onde apesar da imagem de um coletivo colossal, há um sinistro vazio dialógico: trata-se de um dos poucos eventos da vida contemporânea capaz de atrair e reunir tantas pessoas. Não há como não pensar no potencial político deste tipo de encontro não fosse o fato da indiferença massiva reinante no espetáculo coletivo. Diferentemente de eventos musicais coletivos dos anos 60 e 70, como Woodstock, as haves não possuem significação política, ideológica ou cultural relevantes para o resto da sociedade. Não um programa ideológico das eletronic tribes para a sociedade contemporânea, ao contrário dos hyppies. Isto significa algo: o indivíduo ali está disposto a uma maior individuação, e não para uma socialização.

Isto não seria nada grave se, ao mesmo tempo, eventos politicos ou temas de relevância social e política fossem encarados com o mesmo interesse por massas e coletividades. Há neste tipo de manifestação da vida pós-moderna um profundo apelo estetizante da articulação do coletivo, e não-politizante do espaço do coletivo. A efervescência musical está acompanhada da apatia política. Com a intensidade de ruído externo, o silêncio crítico do monólogo interior não tem como brotar. Neste sentido, a palavra não é algo que se pratica em haves: uma have é acima de tudo, e curiosamente, um lugar de silêncio humano, de intenso ruído eletrônico, com breves momentos em que explosões ocasionais de orgasmo eletrônico despontam para romper a monotonia de um ritmo tão acelerado que se torna homogêneo.

A massa é. portanto, conduzida por algo que the coloca suspensa fora de si mesma, e este elemento não é nenhuma utopia, nenhum ideal, nenhum discurso retórico de um orador ou de um político. O novo líder de massas inteiras despediu-se de seu aspecto humano, para encarnar-se na própria sonoridade inaudivel destes eventos... Não é a combinação de ideologias, mas a combinação de ruídos que mobilizam massas contagiadas. Aquele operar fabril do Dj, antes reservado ao estúdio, que se dá ali, sob os

1o A respeito, vide LYOTARD, Jean-François. A condição pós-moderna. Tradução José Bragança de Miranda. 2. ed. Lisboa: Gradiva, 1989. 
olhos de um coletivo imerso numa escuridão, somente salpicada de luzes, controladas por técnicos de iluminação, cujo ritmo de aparição procura seguir a febril demonstração de aceleração musical, recebe o complemento de atuação dos $\mathrm{Vj}$ 's. que oferecem à turba uma imensidão de imagens caóticas, sem sentido, geralmente desencadeadas e soltas. traduzindo-se no todo um cenário curioso de convite a um mundo dominado por impulsões eletrificadas e que remete à dimensão de uma realidade virtual. Há uma elevação, que não é espiritual, mas que se dá em massa a todo toque ritmado que alcança um certo ápice de tempos em tempos.

Este deslocamento de um real a outro é sintomático. A tecnificação alcançou o grau de significação de uma espécie de sublimação, de um nirvana eletrônico. Tornou-se um padrão de contemplação, no transe estético. Ser possuido pela música eletrônica é uma espécie de transe de deslocamento, em que o ritmo predomina acima da capacidade de ossos e músculos reproduzirem todas as repetidas tonalidades e sonoridades compostas pelo $\mathrm{Dj}$. Não há simetria entre o dançado e o ritmado, tudo vale, desde que seja frenético e incorpore o transe coletivo. A sensação do indivíduo imerso na turba e no ruído é a da indiferença de si; se estivesse ali ou não-estivesse, não seria diferente. Tudo estaria do mesmo modo; sua existência é banal, e indiferente, e ele é acima de tudo, ali no meio, impotente. A experiência radical de indiferença é a mesma que se sente e se percebe na vida das ruas das grandes cidades, em meio a ritmos frenéticos de relações de trabalho e fluxos de pessoas, onde medra a impessoalidade, ao lado da indiferença.

A boa música eletrônica é acjuela que diminui o intervalo entre uma martelada e outra, é mais frenética, que suspende o ouvinte no gozo do ápice rítmico intensificado. Trata-se de uma estética por marteladas repetitivas, produzida por um obrar frenético das mãos do Dj... Sua intensidade é anestesiante do cérebro e da audição, e superpassa o indivíduo. Uma ve $z$ entrado. ele desaparece na multidão e diante de seu novo senhor, cuja vocalidade eletrônica ecoa acima da turba. Fenômeno de massas e fenômeno tecnológico, a nova voz do coletivo vem de dentro das máquinas... é anônimo e não-humano. Sua voz é ouvida por todos, mas a voz de todos não se ouve. Mão de única via, qualquer manifestação individual é desintensificada pela reinante e imperante forma de manifestação de império do som eletrônico.

Mesmo se consideradas as drogas mais corriqueiras dos freqüentadores de haves, ainda aqui a curiosidade é grande. A droga é pílula, é insípida, inodora, indolor e incolor. É aquela que faz o "cérebro ferver", na linguagem das tribos. Há uma tecnologia da diversão, uma indústria da felicidade prometida, uma garantia de que o fármaco consentirá sonhos catárticos que retiram o indivíduo da realidade ao sum do elctronismo. 
É a porta de saída da realidade concreta (do mero corpo, das banais relações humanas, das carências afetivas, das necessidades materiais, da ordem do trabalho e do esforço, do sucesso e do insucesso...) para esta outra realidade virtual (do delírio, do deslimite, das sensações incomuns, do deslocamento, do ensimesmamento, do estar possuído por fora, da anestesia geral dos sentidos, da hipersensibilidade, do pulsar frenético assemelhado ao das máquinas, do indolor, da energia além das fronteiras orgânicas e, por isso, inumana). Este fármaco que adrenaliza a vida não é o fármaco do encontro intersubjetivo, mas o do mergulho no mundo da realidade virtual, do êxtase, da suspensão do tempo. Portal de entrada para a realidade que é governada pelo império da vocalidade eletrônica e pela pulsão do ritmo técnico da música eletrônica. O mundo dicotômico platônico. mundo das idéias e mundo das coisas. se reproduz numa nova leitura, em que impera o mundo virtual e mundo real.

À parte o fato de que os entorpecentes são consumidos antes das haves, "para já se chegar na vibe". os indivíduos que as freqüentam se agrupam como abelhas. e se acotovelam no êxtase eletrônico solitário. É um grupo sem grupo, o que importa é esta coletividade pressuposta, pois não se dança numa pista vazia. Com ela não se compartilha nenhuma ideologia, nenhuma vontade politica, por vezes nenhum valor ético; com ela se compartilha o instante do frenesi eletrônico. É este recorte de mundo que sobrevive como elo em meio à indiferença. Este não é um evento para conhecer pessoas, criar laços afetivos ou mesmo para "ficar" Cada um está por si. mesmo que comparecem em grupos ou em massa. Trata-se de um lugar onde as práticas direcionam para a egocentração, cada um a viver a nóia própria.

A questão de um coletivo desmobilizado é algo que de certa forma reclama uma análise mais aprofundada, Mas, ao lado desta questão, que reflete um tanto do individualismo contemporâneo, está também a questão da aceitação de uma linguagem de dominação técnica que soterra o indivíduo. Um trecho de uma dessas canções revela com toda força isto: "I have no memory, every day is a new day, I don't remember the day' before. Mi mind is like a tape recorder... erase...erase ...erase..." 1 . Além de revelar a fragilidade da consciência contemporânea, sua instantaneidade. seu aspecto mais passageiro, contingente e fluido, a não-presença do passado e a inconsciência do indivíduo fora da presentidade eterna do fluir heraclitiano do tempo. revela também que quando a memória é vista como um tape recorder, de fato, ela perdeu a condição de parte orgânica da razão, foi equiparada a um dos equipamentos da tecnologia. A técnica não está somente presente no ambiente. ela determina o indivíduo, atravessando-o, re-definindo sua condição novamente.

Dave Seaman. Renaissance, 2006, Thrive Records, faixa 6. Erase. 4"32' 
Ali se percebe, com clareza, que no lugar da modemidade ter cedido, a modernidade aprofunda ainda mais os seus traços característicos. $\mathrm{O}$ fato de os indivíduos dançarem sob ritmos de evocação cibernética, que definem o apagamento do humano, constrói uma era do louvor à liberdade pelos implementos (celular, lap-top, palm-1op, ipod, internet...). Quem é, é definido pelos implementos que possui e porta. O indivíduo é atravessado pela estética consumista-eletrônica, e, nesta medida, sua identidade é traduzida pelos implementos tecnológicos da vida moderna. ${ }^{18}$ Por ora, estes implementos são todos apêndices do corpo, mas os primeiros testes começam a tornar a tecnologia parte interior do próprio corpo humano. Não-somente o sucesso dos testes de mãos biônicas e tecnologia médica para a cura de doenças, mas também para o incremento do controle por uma prática biopolítica da vida da sociedade de massas, na esteira da crítica à modernidade formulada por Foucault. ${ }^{19}$ São técnicas de controle que passam a exercer a soberania deslocado do território para projetar-se sobre o corpo, e, quando contam com o próprio avanço técnico, tornam-se elementos de práticas políticas de dominação e práticas sociais de despersonalização; digitais para catracas de segurança; leitura ótica da retina para identificação pessoal; código de barras como $R G$ pessoal são apenas exemplos desse processo. Estes são implementos que começam a fazer parte do quotidiano e começam a dar demonstração do que advirá neste campo. ${ }^{2 u}$ Não há um recuo da modernidade aqui, mas o que se constata é um excesso de modernidade, seguindo sua tendência auto-imanente, dialética e contraditória, no que tange ao exercício do controle do corpo. Como afirmam Heller e Fehér: "De hecho, casi todas las principales tendencias dinámicus de la modernidad fueron contrarias ul cuerpo; infravaloraban y somctieron lo corpóreo al mismo tiempo que procuraban

18 "A ideologia hodiema reside em que a produção e o consumo reproduzem e justificam a dominação. Mas o seu caráter ideológico não altera o fato de que os seus benefícios são reais. A repressividade do todo reside em alto grau na sua eficácia: amplia as perspectivas da cultura material, facilita a obtenção das nccessidades da vida, toma o conforto e o luxo mais baratos, atrai áreas cada vez mais vastas para a órbita da indústria - enquanto. ao mesmo tempo, apóia e encoraja a labuta e a destruição. $O$ individuo paga com sacrificio do seu tempo, de sua consciência, de seus sonhos; a civilizaçào paga com sacrificio de suas próprias promessas de liberdade. justiça e paz para todos" (MARCUSE, Herbert. Eros e civilizaçào: uma interpretação filosófica do pensamento de I'rcud. Tradução de Álvaro Cabral. 8. ed. Rio de Janeiro: LTC, 1999. p.99).

19 "Uma das idéias ussenciais de Vigiar e Punir é que as sociedades modernas podem ser definidas como sociedades "disciplinares"..." (DEL.EUZE, Gilles. Foucault. Tradução Claudia Sant Anna Martins. São Paulo: Brasiliense, 1988. p. 34).

20 'El llamado proceso civilizador', cuyo mejor sociologico es Norbert Elias, culmina esa tendencia a expulsar el cuerpo de la vida modema. En el proceso civilizador hay una propensión subyacente que parece autocontradictoria: es equivalenete a los esfuerzos frenéticos destinados a transformar el hábitat humano en auténticamente humanistico eliminando de él todo rastro de la existencia fisica de los humanos " (HELIER, Agnes; FEHÉR. Ferenc. Biopolitica: la modemidad y la liberación del cuerpo. Traducción José Manuel Álvarez, Flórcz. Barcelona: Peninsula, 1995. p. 17). 
reglamentarlo y sustituirlo" 21

Quando este processo encontra no próprio indivíduo o assentimento de que é necessário para se legitimar, percebe-se que a tecnificação alcança seus melhores resultados na produção de corpos docilizados ao poder, na linguagem de Foucault. $\mathrm{O}$ poder tátil, móvel, flexível, migra para dentro da tecnologia e pratica uma biopolítica intra-articulada ao próprio organismo. Trata-se da ascensão de uma cultura do extream na relação entre técnica e humanidade. Não é raro verificar que espetáculos de portadores de piercings pelo corpo são capazes de oferecer: portam implantes e fibras metálicas, distribuem piercings em todas as partes do corpo, utilizam implantes subcutâneos com evocações de formas robóticas ou animais - o indivíduo tecnificado deseja substituir sua pele pela carapaça metálica. Ele mesmo se torna $o$ implemento, e, aos poucos, a rejeição orgânica vai cedendo em direção à aceitação do inorgânico... São usuais atualmente espetáculos e shows de exibicionistas que praticam uma arte sobre o corpo definida como Heavyhodymod. Trata-se de arte de modificar o próprio corpo. Trata-se de uma vanguarda que cultura a body modification culture. Esta transformação também consente uma dinâmica chamada piercing suspension shows, que são espetáculos de suspensão do corpo em que a dor se torna uma espécie de êxtase climática da exposição. ${ }^{22}$ Em parte humano, em parte material metálico, este indivíduo é o estereótipo da penetração tão profunda da ideologia da técnica e da mecânica, da eletrônica e da robótica, que tudo isto se realiza apagando a orgânica expressão da personalidade humana.

Este indivíduo deseja perder algum aspecto de sua humanidade pelo fato de já se ter em grande parte acostumado a substituí-la quotidianamente pela face tecnológica de que se reveste (ele não é ele: é o e-nome; é o seu $e$-code; é o número de

21 HELLER, Agnes; FEHÉR, Ferenc. Biopolitica: la modernidad y la liberación del cuerpo. Traducción José Manuel Álvarez Flórez. Barcelona: Peninsula, 1995. p. 15.

22 Uma demonstração pode ser colhida no texto intitulado Set into a coma, onde se lê do escritor anônimo: "Once the pain left my mind, I started having a lot of fun. The pain had turned into a somewhat euphoric yet intense feeling all around my stomach and legs. My chest still had small amounts of pain which varied from what position my head was in. This also made breathing tricky. It felt as if belts were tightly wrapped around my torso and legs. I had one of the artist slowly turn the rig so that I could watch everything spin around me. It was a weird feeling to watch the room spin around me as nothing but hooks held me in the air. You could easily tell I was having a great time by the expression of my face. After what felt like 30 minutes, I started feeling a bit nauseous. My head was tilted back(it felt better to me,) allowing blood to flow to it faster. We raised my head rest up a bit which helped a lot but I decided to come down at that point. I was lowered to the fluor and when I was down, my body felt as if it were 100 pounds heavier. The hooks were taken out and I was bandaged up before the blood could get too messy. They said that I was up for at least an hour to an hour and a half". Disclaimer: The experience above was submitted by a BME reader and has not been edited. We can not guarantec that the experience is accurate, Iruthful, or contains valid or even safe advice. We strongly urge you to use BME and other resources to educate yourself so you can make sufe informed decisions. Disponivel em: <http://www.bmezine.com/ritual/A60930/ritsetin.html>. Acesso em: 18 out. 2006. 
identificação: é a autorização da fibra ótica do cartão de crédito; é o seu perfil de comunidades eleitas no orkut). O processo de despersonalização e de criação de uma cadeia de reconhecimentos eletrônicos da personalidade avança de vento em popa. Não se estranha que esta cena se torna cada vez mais corriqueira: "Mas, eu estou dizendo que sou eu!" -- diz a pessoa apressada ao segurança do edificio; "Não, mas se o senhor esqueceu o seu crachá, o senhor não existe" - responde o segurança, no cumprimento de seu papel de ratificador de funcionamento do sistema. O humano começa a desaparecer e é substituído paulatinamente pelo apelo ao robótico.

A submissão à técnica visita cada vez esferas mais intimas e cada vez mais profundas da intimidade do indivíduo, definindo-o como automutilador de sua própria identidade do humano, de uma identidade que se transfere para o que possui sobre si ou dentro de si, este outro elemento externo que se torna interno, por um ato subjetivo de submissão do corpo à tortura da técnica. Mas, isto é somente um dos desdobramentos estéticos radicais da vida contemporânea, que acentua e aprofunda cada vez mais a dimensão da tecnificação. ${ }^{23}$

4. A ritualidade técnica do Direito e a questão da justiça

Se há muito de robótico, técnico e neutralizador do humano na estética e nas práticas culturais contemporâneas, estariam as práticas de justiça seguindo o mesmo caminho? Esta pergunta é encaminhada pela chave-hermenêutica anteriormente construída, e a resposta parece já estar apontada. No entanto, resta compreender como se dá a expressão da tecnificação moderna aqui, neste outro espaço de práticas sociais, que são as práticas de distribuição de justiça. No sentido deste empreendimento, parte-se em direção à análise a partir de uma intuição clara do problema, a intuição de que há uma irreversível sensação de ritualização capaz de produzir uma estéril condição de exercicio reflexivo no exercício da responsabilidade de julgar.

$\mathrm{E}$, de fato, percebe-se que a perda das raízes espirituais de clementos como justiça c igualdade, que estão presentes no discurso da tecnologia judiciária, se faz notória. Esta perda semântica é de causar certa estranheza, e comprimir a análise para a busca de compreensão deste processo de de-significação do uso das próprias palavras. Elas são apropriadas e re-apropriadas em diversos contextos, mas nulificadas na

No sentido do aprofundamento desta experiência da planilicação, da racionalização e da tecnificação, leiase: "... Asi como toda vida ticnde hoy cada vez más a sumeterse a la racionalización y a la planificación, la vida de todo individuo, incluyendo sus impulsos más secretos, que antes conformaban su esfera privada, tiene que adecuarse a las exigencias de la racionalización y de la planificación: la auto conservación del individuo presupone su adecuación a las exigencias de la conservación del sistema. No queda ya espacio alguno para evadirse del sistema..." (HORKHEIMER, Max. Crítica de la razón instrumental, cit., p. 118). 
produção de efeitos semânticos, na medida em que invocadas aqui e ali aleatoriamente. Quando se fala em justiça se está falando de justiça, ou se está falando de sentença? Equivalências semânticas como justiça material e justiça processual se tornam correntemente usuais. Quando se fala de igualdade, se está falando de igualdade, ou se está falando de eqüidistância processual? Igualdade material e igualdade processual são tomadas como equivalentes. Essa de-significação do uso das palavras, que as trivializa e as miniaturiza, se percebe como sendo um registro crescente de despersonificação e desumanização das práticas judiciárias. Estas práticas judiciárias são aquelas construídas ao longo do processo de afirmação da própria modernidade do positivismo jurídico. $\mathrm{O}$ positiviosmo se responsabilizou por transformar justiça em técnica, através de uma racionalidade dogmática que encampou crescentemente o processo de definição do justo pelo legal e pelo formal. Na análise de Horkheimer, a formalização da razão foi o primeiro grande passo para o sancionamento e formação de uma cultura capaz de praticar a perda das raízes dos fenômenos: “... ¿Cuáles son las consecuencias de la formalización de la razón?' Justicia, igualdad, felicidad, tolerancia, todos los conceptos que, como va se dijo, latian en siglos anteriores en el corazón de la razón, o tenían que ser sancionados por ella, han perdido sus raices espirituales..." 24

O Judiciario-fordista é também uma emblemática revelação do espírito da modernidade. Os modelos de produção-em-série da Revolução Industrial se tornam cada vez mais uma marca do modelo de atuação da própria distribuição de justiça. A ascensão da modernidade como era da técnica se revela aqui como a mesma que no âmbito econômico detonou suas formas de manifestação ao longo dos séculos XVII e XVIII. Sob o manto da ideologia do positivismo, que enaltece o progresso, a ciência e a razão descolorida da técnica e da lógica, este quintessenciação da forma avança, alcançando o discurso jurídico. A divisão do trabalho, a fúria do mercado, a competitividade das leis de inserção em relações de trabalho, a mudança dos métodos produtivos, tudo isto está girando em torno do processo de desidentificação da condição humana. Na análise de Horkheimer: "La transformación total del mundo en un mundo que lo es más de medios que de fines es ella misma consecuencia de la evolución histórica de los métodos productivos. Al tiempo que la producción material y la organización social se vuelven cada vez más complicadas y coisificadas, resulta cada vez más dificil reconocer los medios como tales, ya que cobran la apariencia de entidades autónomas...." 25

Num Judiciário de modelo fordista, em cada especialista se faz um fragmento do procedimento, do técnico judiciário ao juiz, do contador ao promotor

2.4 HORKHEIMER, Max. Critica de la razón instrumental. cit.. p. 60.

Id. Ibid., p. 122 
público, a esteira de produção somente não pode parar. Cada indivíduo age na dimensão de sua responsabilidade pessoal, mas se perde a essência do que se tem de fazer, ou mesmo da idéia de que ali se faz justiça, como troca humana. A justiça é distribuída neste modelo do mesmo modo como radinhos de pilha são produzidos. As sentenças em série são somente a revelação de que tudo se tornou um integrado processo de trituração em massa de conflitos humanos, de tudo aquilo que a sociedade hodiema não processou ou digeriu. Este processador de dejetos humanos é o lugar de realização da justiça que se tecnifica em processo de reprodução contínua de fórmulas e idéias preconcebidas. Tribunais são transformados em instâncias para chancelar o modo de atuação fabril da justiça. Mas, afinal, estão fazendo justiça?

Em tempos de exaltação do homem-máquina e da apologia do tecnologismo, não é de se estranhar que a justiça seja tecnificada. Pessoas não são pessoas, são réus, processos não são demandas sociais pois se tornaram números, sentenças não são atos humanos, pois também se tornaram textos despersonalizados e virtualizados (conversíveis em windows ou $p d f$, tanto faz). Neste contexto, de afluxos massivos de demandas, a imagem de juizes soterrados em meio a montanhas de papéis tem se tornado uma imagem cada vez mais corriqueira da vida contemporânea. A despersonalização da figura do juiz é a clara demonstração do desencadeamento da desuminação da justiça. Máquinas cospem sentenças e ditam o ritmo (matricial das impressoras) e a qualidade (gráfica) da justiça que se tem. O importante é ter o documento! O que foi feito nas relações sociais? Isto está em segundo plano.

A justiça que se faz é uma justiça no papel e, mais do que isto, de papel, pois não se decodifica de decisão nominal em decisão social. Phrónesis, mas o que é isto mesmo? Este termo se torna um estranho no ninho, quando se trata de pensar a tecnificação da entrega de justiça.

O processo, nestas condições, se torna o palco no yual se encenam os últimos suspiros da justiça como um atributo humano que sossobra ante a técnica. O que pode ser escrito também pode ser apagado no computador. Esta contigencialidade da informatização da entrega de justiça também leva ao desenvolvimento de uma consciência da inconsciência do justo. e o operacional acaba por se superpor ao substancial nas decisões de justiça. Trata-se de uma contingencialidade que se transfere da forma do sistema ao objeto do sistema. de modo a contaminar a visão daqueles que operam dentro do sistema. Tudo se torna banal, num toque de teclado... A informatização se torna também a windowsização da justiça. Aquilo que foi feito para libertar também prende, e esta é a lógica da modernidade. Isto porque a própria técnica ganhou vida própria e é em função dela que o resto passa a se guiar. $\mathrm{O}$ instrumento antes colocado a 
serviço da liberdade, se torna o controlador da própria liberdade. Como afirma Horkheimer: "La máquina ha prescindido del piloto; camina ciegamente por el espacio a toda velocidad. En el momento de su consumación, la razón se ha vuelto irracional $y$ tonta..." 26

Há um processo de estrangulamento do decisum a produto judiciário, ao mesmo tempo em que se reconhece uma reificação crescente das práticas de justiça. $\mathrm{O}$ Estado se torna um prestador de produtos de justiça, despejados numa maré diária de processos que empanturram como incômodo oneroso as prateleiras das repartições públicas. Despachar rapidamente enviar também rapidamente para o incinerador o entulho processual sobressalente das prateleiras. As massivas quantidades de processos são solvidas com tomadas de decisão que encerram no papel os conflitos, mas os mantêm em suspenso na dimensão da vida social. Pede-se mais e cada vez mais da justiça e ela oferece menos, cada vez menos... O próprio direito que se tem é objeto, é produto, produto do maquinário tecnocrático da operação de todos os atos encadeados do sistema. E, de repente, se acorda de todo este sonho: "Dr... Dr... Dr... Pronto! Tome, a sentença do juiz está pronta!". A esteira de produção se encerrou, e justiça foi feita...

Os operadores do Direito (a expressão é proposital!) acorrem em massa aos föruns, assim como às have as cibertribos. Os operadores também consomem seus entorpecentes previamente, antes de ir ao fórum despachar a petição ou praticar algum ato processual. Seus entorpecentes prévios são a carga de conceitos prévios, tecnologias operatórias aprendidas, métodos e modelos de atuação, códigos de conduta judiciária e pressões de mercado sobre resultados de trabalho... elementos que reunidos criam a tácita aceitação da mecânica da justiça como tal. Este é o ópio do jurista (operador do Direito). Também no fórum - lugar de encontro dos operadores - como abelhas se acotovelam diante dos balcões de cartórios ou salas de espera de audiência, numa espécie de transe coletivo na mecânica acelerada e operativa-procedimental do direito que se tem.

O bom processo é aquele no qual o intervalo do ruido produzido pelos carimbos cartoriais ordinatórios diminui entre si, levando o advogado ao êxtase processual. Justiça boa é justiça célere (qual o sentido da inserção do inciso LXXVIII ao art. $5^{\circ}$. da CF, 88), para as partes e para os advogados. Justiça boa é justiça estatística, métrica e quantitativamente produtiva. para o Tribunal e para o CNJ. Por aí, se mede o bom juiz da era da produção em massa de sentenças. Trata-se da emergência da figura do juiz-máquina (aquele que realiza 40 audiências-dia, despacha 30 processos-dia, expede sentenças-modelo e dá continuidade a práticas repetitivas), e tudo isto está a evocar a

HORKHEIMER, Max. Critica de la razon instrumental, cit., p. 143. 
imagem chapliniana da modernidade, que contorce e retorce todo o valor à funcionalidade do sistema. Onde o lugar para o humano quando as máquinas falam por si?

A ênfase está posta no resultado. Trata-se da lógića da eficiência, combinada com uma ética de fins. Estes dois modelos são claramente extraídos dos métodos de produção, o que testifica sua incômoda presença no ambiente judiciário como manifestação do Habermas costuma chamar de colonização do mundo da vida pela razão instrumental. A interação não é verdadeira, não é interação comunicativa propriamente dita; responde-se a uma racionalidade de fins, no operar tumultuada da justiça que se faz na sociedade de massas, esta meia-justiça que está muito aquém de poder responder aos desafios da sociedade complexa hodierna. O juiz também se torna. ele mesmo, alguém de profundo apelo estatístico. A estatistica de Estado se torna o método de calcular rendimento profissional e merecimento promocional. Emerge a figura de um juiz que age de acordo com uma racionalidade estatística, ou seja, de uma prudência judicial quantitométrica. O melhor desempenho significa o maior número de processos despachados; há um condicionamento para que se fale a linguagem da produtividade, ao lado da linguagem da eficiência técnico-racional. Então, o vocabulário das práticas judiciárias passa a evocar um novo dicionário, o dicionário da justiça da era técnica, e os termos em evidência são: celeridade; quantidade; produtividade. Tudo está a ser tornado parte de um mais amplo processo de desumanização, de banalização, em que a efemeridade da vida contemporânea se retrata nas práticas judiciárias, de uma modernidade que se revela liquida e liquefeita, para empregar a linguagem de Zygmunt Bauman, na qualidade da justiça que se percebe na lida diária com o processo.

É da frieza e da indiferença que, em grande parte, surge a justiça advinda da modernidade. É da impessoalidade do processo. da litigância mediada, do ódio drenado pelas fileiras infinitas de documentos e papéis dos autos que nascem e brotam as soluções formais aos litígios da vida hodierna. O mundo tem pressa. O capital tem pressa. A eficiência é o modo de encaminhamento desta lógica. Nada disso discrepa do modo como o fordismo produziu eficiência nas esteiras de produção industrial, para maximizar o lucro e melhorar o desempenho produtivo das indústrias no processo de afirmação do capitalismo.

O juiz. neste sentido, está blindado, está protegido pelu procedimento, pela forma, bem como pelo alto nivel de objetivações rituais, para produzir uma justiça também ritualizada, legalizada, burocratizada, no exercício claro do método de dominação da modernidade que praticada a forma de dominação weberiana legalburncrática. Historicamente. foi o positivismo jurídico que produziu os mitos que 
haveriam de transformar a própria condição do individuo-juiz, em seguida tornado o juiz-técnico pois se tratava de uma batalha contra a irracionalidade, de onde se parte em direção a uma aventura onde se obtém o juiz-máquina, pelo excesso de racionalidade técnica do sistema, e da administração, cada vez mais ritualizada da própria justiça. ${ }^{27} \mathrm{Da}$ irracionalidade pela carência de razão, na acusação do discurso do século XVIII, ${ }^{28}$ caminhou-se em direção à irracionalidade por excesso de razão. A mediação entre o indivíduo-juiz e o juiz-máquina está no logicismo, no abstracionismo, no distanciamento, no formalismo do mito construído pelo discurso positivista do juiz-técnico. ${ }^{29}$

Alguém dirá: esta é a justiça possível! Não, esta é a justiça que foi tornada assim por um conjunto de condições sócio-históricas, por um conjunto de decisões humanas, que uma vez feitas, também podem ser des-feitas e re-feitas. Por isso, urge pensar quais as alternativas em direção à retomada da autonomia, da autonomia perdida com o incremento da técnica sobre a razão.

\section{A retomada da autonomia judiciária}

Tudo está a indicar que a aplicação da justiça demanda um artesanato complexo. A perda da autonomia do poder do subjetivo transformador, porque consciente e crítico, se neutraliza na dimensão da superafetação do sistema por um processo de inflacionado tratamento de processos em massa e da tecnificação crescente e especializada do discurso judiciário.

A autonomia no Judiciário caminha no sentido da recuperação da humanização dos procedimentos e na implementação de condições de superação do predomínio da razão instrumental no domínio das práticas judiciárias. A evitação da

27 "É uma opinião geralmente admitida, entre os lógicos contemporâneos, a de que cabe identificar a lógica com a lógica formal. Compreende-se muito bem isso se se considera a evolução da lógica desde meados do século XIX. Esse ramo da fillosofia recobrou vida e vigor por estimulo de matemáticos tais como Boole, Morgan, Scluröder, Frege, Peano, e se identificou cada vez mais, com uma álgebra generalizada, o que lhe valcu, aliás, em vários autores, o nome de lógica matemática“" (PERELMAN. Chaim. Ética e direito. Tradução Maria Ermantina Galvão G Pereira. São Paulo: Martins Fontes, 1990. p. 469).

28 Vide PERELMAN, Chaim. Ética e direito, cit, p. 506.

29 Neste sentido, a análise de Horkheimer aponta no sentido destas transformações: “... El intelecto humano, que tiene raices biológicas y sociales, no es una entidad social absoluta, separada e independiente. Sólo fue caracterizada como tal en la estela de la división social del trabajo, para justificar esta por recurso a la constitución natural del hombre. Elevadas a la condición de intelecto puro, las funciones directivas de la producción - dar órdenes, planificar, organizar - fucron contrapuestas a las funciones matcriales de la producción, asumidas como una forma baja, impura, de trabajo, el trabajo de los esclavos.

La neutralización de la razón, que sustrae a la misma toda relación con un contenido objetivo y la fuerza de juzgarlos, degradándola asi a la condición de mera capacidad ejecutiva más volcada al cómo que al qué, la transforma de modo creciente en un mero aparato obtuso para el registro de hechos. I. a razón subjetiva pierde toda espontaneidad, toda productividad, pierde la fuerza necesaria para descubrir contenidos de nuevo tipo y conferirlos vigencia, pierde lo que comporta su subjetividad..." (HORKHEIMER. Max. Critica dé la razón instrumental, cit., p. 85). 
barbárie é também um resultado de uma atitude da razão, mas de uma forma de razão emuncipátória, que cuida contra a barbárie, esta que já pôde se manifestar em plena civilização, através de Auschwitz. "A única força verdadeira contra o principio de Auschwitz seria a autonomia, se me for permitido empregar a expressão Kantiana; a força para a reflexão, para a autodeterminação, para o nâo deixar-se levar" afirma Adorno. ${ }^{i u}$

A evitação da redução da racionalidade judiciária, de uma racionalidade emancipatória a uma racionalidade instrumental, faz parte de um processo de luta por justiça na contra-marcha da inércia diária, na qual caminha o funcionamento do sistema atual. $^{31}$

Neste sentido, ressente-se de um déficit de racionalidade reflexiva, em função de amarras burocráticas de um sistema cerrado sobre suas próprias limitações, além de déficits estruturais elementares, que são os grandes óbices contemporâneos ao exercício da justiça concreta. Perdeu-se algo de que os romanos tinham conhecimento, a idéia de que o Direito é ars boni et aequi, ou seja, atividade deliberativa. arte que envolve pensamento, reflexão, prudência, análise contextual, tomada de decisão inserida na articulação concreta. Da ars à manus, há uma transferência, e o Direito se converte cada vez mais em trabalho manual, em operar, em técnica e processo. em esteira de produção. O juiz se torna o protagonista deste operar técnico; o Dj das haves. Coordena processos operatórios, somatórios de ações técnicas especializadas que rendem o espetáculo como um todo. O fórum. o lugar de comparecimento obrigatório e massivo. lugar de encontro do operariado do sistema jurídico, tomado na turba de ruídos da vida contemporânea e, insensiveis se tornam. eles mesmos, às questões de justiça. Afinal, o sistema é assim!

No entanto, quando se pensa na reversão deste quadro, se deve recorrer a indivíduos capazes de crítica e de reflexão. A autonomia está articulada a esta compreensão de que uma modernidade emancipatória se perdeu e cedeu a uma uutra modernidade instrumental. No entanto, quando se percebe que o perfil das pessoas que buscam carreiras públicas, e acorrem aos concursos públicos (magistratura, procuradoria, promotoria, defensoria...) o fazem geralmente motivados por uma ética da estabilidade financeira... é claro que tudo isto somente contribui para empobrecer ainda

30 ADORNO. Theodor W. Palavras e sinais. Tradução Maria Helena Ruschel. Petrópolis: Vozes, 1995. p. 110.

“... Posteriormente, el contenido de la razón pasa de modo arbitrario a ver reducidas sus dimensiones a la una sola de sus partes. al menos a la de uno solo de sus principios; lo particular pasa a ocupar el lugar de lo general. Este tour de force en el ámbito de lo espiritual prepara el terreno para el dominio de la violencia en el ámbito de lo político. Una vez despojada de su autonomia, la razón se ha convertido en un mero instrumento..." (HOR KHEIMER, Max. Critica de la razón instrumental, cit.. p. 58). 
mais o horizonte futuro para a possibilidade de mudanças desse quadro. Indivíduos também previamente derrotados pela sociedade expurgam suas derrotas e pessimismos, através de um ato de renúncia à luta por espaço no mercado, trocado por um espaço dentro do Estado-provedor.

Somente haveria alternativa nos rumos em direção à autonomia judiciária se se tornasse possivel a substituição do modelo fordista pelo modelo fronético de Judiciário. O elemento da phrónesis, como meio de produção de decisões ético-jurídicas, parece ser um ingrediente fundamental à quebra do abstracionismo legalista e sistêmico, operatório e continuísta, herdado da modemidade positivista. A evocação do termo grego, na leitura perelmaniana, é também bastante significativo. As alternativas, mais próximas, mais humanas, mais pessoais (Juizados Especiais, Projetos de Prevenção de Litígios, Mediação, Arbitragem...), mesmo assoberbadas e defeituosas, parecem retratar a tentativa de reação à cultura processual inflacionada de modernidade e de racionalidade instrumental.

O que há de humano na condição da própria prudencialização da justiça é o fato do exame apurado, minucioso e sempre mais detalhado pressupor uma necessária produção de condições de humanização do próprio processo. Por isso, a prudencialização acaba sendo uma espécie de movimento ético de resistência, um movimento ético-politico de recusa aos excessos de modernidade, na esteira do que vem afirmando Habermas, ainda que em outros capitulos de sua obra. ${ }^{32}$

$\mathrm{O}$ juiz, neste modelo, pode ser identificado como sendo a justiça animada. E isto, de fato, porque o juiz é o responsável pela aplicação da justiça corretiva. " Se as partes se desigualam, cumpre ao juiz restabelecer a igualdade. Por isso, a simbologia fundamental da magistratura reside na balança com o reto (rectum) em posição ereta. Justiça reclama ponderação e não-mecanicismo. O juiz representa a imparcial e

\footnotetext{
O capitulo da obra é de discussão dos processos de engenharia genćtica: "A recomendação implicita é evidente: seria melhor reconhecer aquele resto de sentimento arcaico. que subsisturia na aversão 'as quimeras produzidas pela técnica genética, ao seres humanos cultivados e clonados e aos embriōes utilizados em experiência. Por certo, podemos ter um quadro totalmente diferente se entendemos a "moralização da natureza humana" no sentido da auto-afirmação de uma autocompreensão ética da uspécie, da qual depende o fato de ainda continuarmos a nos compreender como único autores de nossa historia de vida e podemos nos reconhecer mutuamente como pessoa que agem com autonomia. A tentativa de prevenir, mediante recursos jurídicos, que nos acostumemos a uma eugenia liberal, que vai se instalando lenta e discretamente, e de garantia à procriação, ou seja a lusão de sequeências de cromossomos dos pais. um certo grau de contingência ou naturalidade seria algu diferente da expressão de uma resistência apática è antimodernista. Como garantia das condiçōes de preservação da autocompreensão prática da modernidade. essa tentativa seria, antes, um ato político de uma ação moral relativa a si mesma. Certamente, essa concepção combina com u quadro sociológico de modernidade que tenha se tornado reflexiva" (HABERMAS, Jürgen. O futuro da natureza humana. Tradução Karina Jannini. São Paulo: Martins Fontes, 2004. p. 36).

3. Aristóteles. Ethica Nicomachea, 1132a, $6 / 7$.
} 
eqüidistante personificação da justiça (grego, dikaion émpsychon). ${ }^{34}$ É mediador, pois. representa uma mediedade, um termo medianeiro entre dois interesses opostos. O humanismo que se requer em sua formação não é algo que se exige desmotivadamente. pois a lógica da atividade julgadora é uma lógica humanista e do razoável, com apelo para a prudência e para a capacidade de adequação de plúrimos fatores; o juiz preparado mnemonicamente para aplicar leis não é, certamente, o melhor perfil de profissional para o exercício desta lógica. De fato, esta lógica, a lógica do razoável, é a lógica jurídica, pois, neste terreno não se pode pleitear juizos de certeza e evidência absolutas, o que demanda ainda maior prudência por parte da autoridade julgadora. A reação, no sentido habermasiano de construção de uma ética de responsabilidade, é necessária como forma de responsabilização e autoconsciência, termos que se tornaram também raros na experiência contemporânea. ${ }^{35}$

Conclusões

A análise acima desenvolvida permitiu entrever o quanto os avanços da modernidade se expandem também para a dimensão das práticas de justiça. Também foi possivel detectar. pelo estudo das práticas estéticas, que a técnica consuma o homem, assim como juízes são consumados pela racionalidade do sistema. Por isso, torna-se fundamental repetir com Perelman: "Com efeito, o juiz não é um autômato: concede-sethe um poder de apreciação, condição de seu poder de decisão. A qualidade que se exige dele é ter discernimento, ou seju, ser capaz de apreciar os diferentes aspectos de um problema, de pesar o pró e o contra. Se u justiça pudesse dispensar o julgamento, se se pudesse mecaniza-la, as ináquinas poderiam dizer o direito de uma forma muito mais rápida e muito inenos onerosa do que o homem. Mas as máquinas não têm discernimento, sendo por isso que, em todas as situações delicadas, o recurso ao juizé indispensável" 36

São Paulo, novembro de 2006.

\footnotetext{
34 Aristóteles, Ethica Nicomachea. 1132 a, 20.

35 "Não se trata de uma atitude de crítica cultural aos avanços louváveis do conhecimento cientifico, mas apenas de saber se a implementação destas conquistas afetam a nossa autocompreensão como seres que agem de forma responsável e, em caso afirmativo. de que modo isso se dá". (HABERMAS, Jürgen. $O$ fuluro da natureza humana. Tradução Karina Jannini. Sào Paulo: Martins Fontes, 2004. p. 18).

36 PERELMAN. Chaim. Élica e direito, cil., p. 513.
} 


\section{Referências}

ADORNO Theodor W. Palavras e sinais. Tradução Maria Helena Ruschel. Petrópolis: Vozes, 1995.

- Prismas: crítica cultural e sociedade. Tradução Augustin Wernet e Jorge M. B. de Almeida. São Paulo: Ática, 2001.

ARENDT, Hannah. A condição humuna. Tradução Roberto Raposo. 10. ed. Rio de Janeiro: Forense Universitária, 2000.

BAUMAN, Zygmunt. Ética pós-moderna. Tradução João Rezende Costa. São Paulo: Paulus, 1997.

- Amor Liquido: sobre a fragilidade dos laços humanos. Tradução Carlos Alberto Medeiros. Rio de Janeiro: Jorge Zahar, 2004.

Em busca da política. Tradução Marcus Penchel. Rio de Janeiro: Jorge Zahar. 2000.

O mal-estar da pós-modernidade. Tradução Mauro Gama; Cláudia Martinelli Gama. Rio de Janeiro: Jorge Zahar, 1998.

- La globalización: consecuencias humanas. Tradução Daniel Zadunaisky. 2. ed. México: Fondo de Cultura Económica. 2001.

Modernidade liquida. Tradução Plinio Dentzein. Rio de Janeiro: Jorge Zahar, 2001. . Modernidade e ambivalência. Rio de Janeiro: Jorge Zahar, 1999.

BENJAMIN, Walter. Obras escolhidas. Tradução Sergio Paulo Roaunet. 7. ed. São Paulo: Brasilense, 1994.

BITTAR, Eduardo C. B. O direito na pós-modernidade. Rio de Janeiro: Forense Universitária, 2005 .

DELEUZE, Gilles. Foucault. Tradução Claudia Sant'Anna Martins. São Paulo: Brasiliense, 1988.

HABERMAS, Jürgen. O futuro da natureza humana. Tradução Karina Jannini. São Paulo: Martins Fontes, 2004.

HELLER, Agnes; FEHÉR, Ferenc. Biopolitica: la modernidad y la liberación del cuerpo. Traducción José Manuel Álvarez Flórez. Barcelona: Península. 1995.

HORKHEIMER, Max. Critica de la razón instrumental. Buenos Aires: Ed. Sur, 1973. 
HORKHEIMER, Max; ADORNO, Theodor W. Dialética do esclarecimento: fragmentos filosóficos. Tradução Guido Antonio de Almeida. Rio de Janeiro: Jorge Zahar, 1985.

LYOTARD, Jean-François. A condição pós-modernu. Tradução José Bragança de Miranda. 2. ed. Lisboa: Gradiva, 1989.

MARCUSE, Herbert. Eros e civilização: uma interpretação filosófica do pensamento de Freud. Tradução de Álvaro Cabral. 8. ed. Rio de Janeiro: LTC. 1999. 